\title{
A PRELIMINARY STUDY ON SHEAR CAPACITY OF HISTORICAL REINFORCED CONCRETE BEAMS
}

\author{
F. PALMISANO \\ Politecnico di Bari, Bari, Italy.
}

\begin{abstract}
In European cities there are many reinforced concrete (RC) constructions belonging to the early 20th century and, in most cases, these pieces of work so rich in historical, architectural and cultural significance urgently require maintenance and restoration.

Reinforced concrete works, from the origins until the release of the first technical standards, were built by applying patented systems (e.g. Monnier's, Hennebique's) that were often the result of individual intuitions more than scientific and technical knowledge. This is one of the reasons that many of the structures built in those years, and still surviving, could not be considered reliable with regard to the structural safety, as it is presently intended.

In this scenario, the evaluation of RC beam shear capacity becomes crucial. In this article, analysing the tests carried out in Stuttgart in the early 20th century, a preliminary study on the shear capacity assessment of historical RC beams is presented. The aim is to verify the applicability to these kinds of beams of the relations given for new constructions in the present codes. Moreover a novel formulation for the transversal shear capacity for historical RC beams with U-shaped plates is proposed.

Keywords: Load Path Method, reinforced concrete, shear capacity, Strut-and-Tie Model
\end{abstract}

\section{INTRODUCTION}

The main task to be faced in the restoration of the early RC constructions is the assessment of their actual structural capacity, in order to provide the proper guidelines for retrofitting, rehabilitation and conservation.

It is not so straightforward to apply to ancient concrete structures the same methods of analysis that are used for the design of new constructions, and this is particularly true with regard to shear capacity. In fact, models and formulations used in the standard design practice are mainly based on the experimental observation of the behaviour of real-scale structural elements that are different from those of the early RC constructions. The constructive technique and the structural details concerning the shear reinforcement have changed much in the last century, much more than those regarding longitudinal reinforcement.

Present methods to evaluate shear capacity seem to be not applicable to old RC structures mainly due to the following reasons:

- the chemical characteristics of the steel reinforcement and, in particular, the low Carbon content that makes the collapse cracking pattern be typical of concrete structures with high ductility reinforcement;

- the technology and, in particular, the type of shear reinforcement that consisted of open U-shaped plates which are not able to confine the inclined struts of the resisting internal truss.

Therefore, the approach to shear capacity assessment should necessarily start from a critical review of the different formulations and from an analysis of the available experimental tests on historical structures. Many tests have been performed all over the world in the early 20th century (e.g. [1-3]) to evaluate the shear capacity of RC beams. Since then the 
approach to shear design has been modified many times introducing different formulations in the codes. At present many studies are in progress to evaluate the flexural and shear capacity of old historical RC beams (e.g. [4, 5]).

In this scenario, the first part (i.e. paragraph 2) of this article aims to analyse if the current shear formulation of Eurocode 2 [6] is applicable to the RC beams tested in Stuttgart by Emil Mörsch in 1906-1921 [1]. The choice of the code and of the tests is not casual. In fact, the Eurocodes are the technical standards adopted in almost all European countries and the above-mentioned tests were considered as a 'reference point' in Europe in the early 20th century. However, since the first part of this article is based on a small subset of tests, verified with only two codes (i.e. $[6,7])$, this part can be considered as a preliminary study.

In the second part of the article (i.e. paragraph 3) a novel formulation, based on the Load Path Method (LPM hereafter) [8], for the transversal shear capacity of historical RC beams with U-shaped plates is proposed.

\section{ANALYSIS OF THE SHEAR TESTS PERFORMED IN STUTTGART}

The data and the results of some shear tests performed by Mörsch [1] in Stuttgart from 1906 to 1921 are summarized in Table 1 . In this table:

- $f_{\mathrm{c}, \mathrm{cube}}$ is the cubic concrete compressive strength;

- $f_{\mathrm{t}}$ is the reinforcement tensile strength;

- $b_{\mathrm{w}}$ is the web width;

- $h$ is the overall depth of the cross section;

- $\phi_{1}$ is the longitudinal reinforcement diameter;

- $n_{1}$ is the number of longitudinal bars;

- $\phi_{\mathrm{w}}$ is the shear reinforcement diameter;

- $n_{\mathrm{w}}$ is the number of links of shear reinforcement;

- $s$ is the longitudinal spacing of shear reinforcement;

- $V_{\text {u,test }}$ is the ultimate shear strength of the tests.

All beams were simply supported, their span was $3 \mathrm{~m}$ long and they were loaded with two point loads applied at one-third of the span. They had ' $T$ ' transversal section with the following dimensions for the top flange:

- Tests 4-23: thickness $=10 \mathrm{~cm}$; width $=50 \mathrm{~cm}$.

- Tests 75, 77: thickness $=10 \mathrm{~cm}$; width $=45 \mathrm{~cm}$.

For further details on the tests, see Ref. [1].

Many approaches to the shear capacity are present in the literature and in other codes (see, e.g. [5-7, 9-12]). In this paragraph the test results in Table 1 have been analysed by using the models of the last two releases of Eurocode 2 (i.e. [6, 7]). This is why this part of the article has to be considered as a preliminary study.

In particular, the last release of both the Eurocode 2 [6] and the Italian technical standards [13] adopt the 'truss model' with variable strut angle $\theta . V_{\mathrm{Rd}, \max }$ is the design value of the maximum shear force which can be sustained by the member, limited by crushing of the compression struts, and $V_{\mathrm{Rd}, \mathrm{s}}$ is the design value of the shear force which can be sustained by the yielding shear reinforcement: 


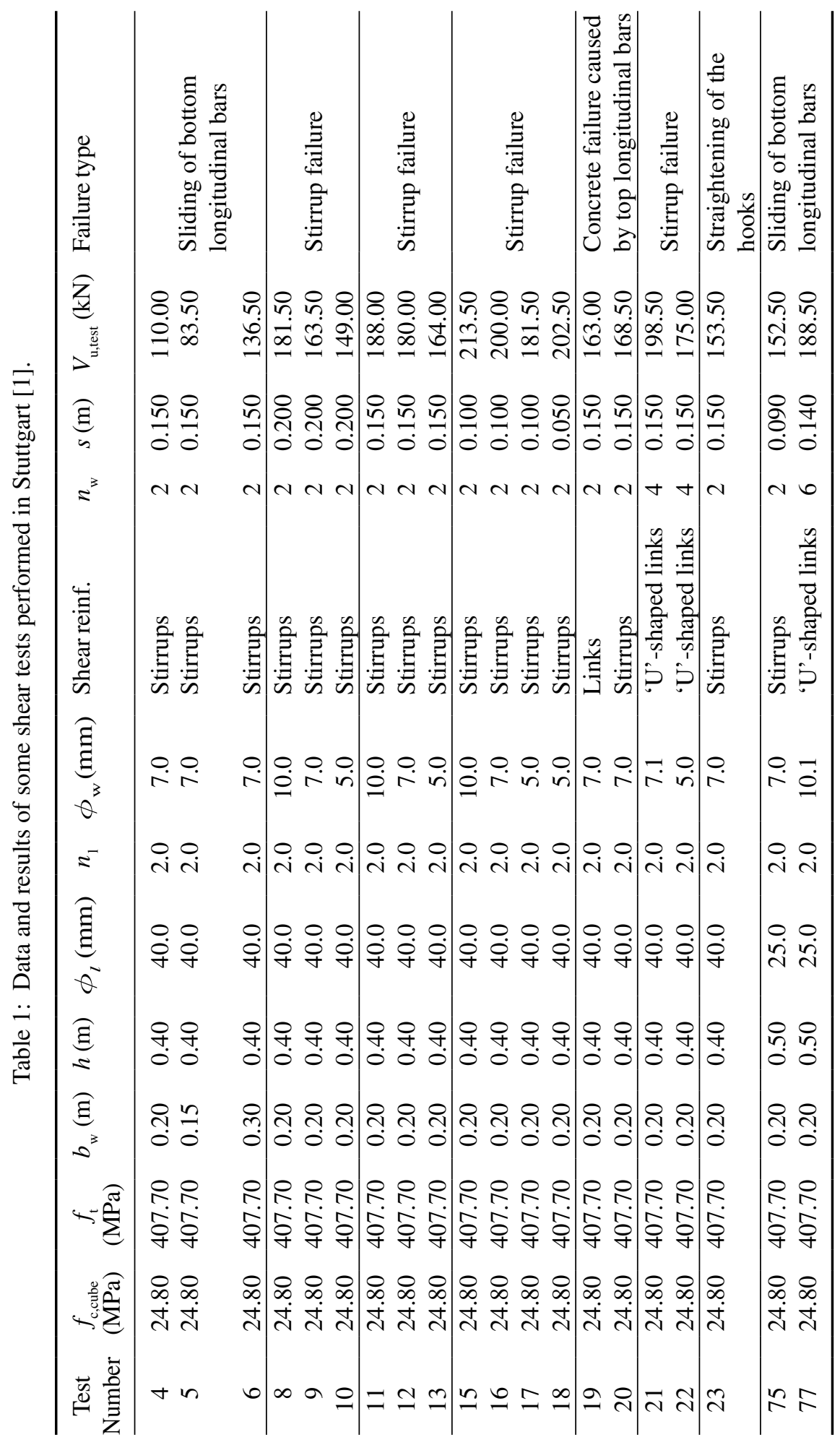




$$
\begin{gathered}
V_{\mathrm{Rd}, \max }=v f_{\mathrm{cd}} b_{\mathrm{w}} z \frac{\operatorname{ctg} \theta+\operatorname{ctg} \alpha}{1+(\operatorname{ctg} \theta)^{2}} \\
V_{\mathrm{Rd}, \mathrm{s}}=f_{\mathrm{ywd}} \frac{A_{\mathrm{sw}}}{s} z \sin \alpha(\operatorname{ctg} \theta+\operatorname{ctg} \alpha)
\end{gathered}
$$

where

- $\alpha$ is the angle between shear reinforcement and the beam longitudinal axis perpendicular to the shear force;

- $\theta$ is the angle between the concrete compression strut and the beam axis perpendicular to the shear force;

- $\nu f_{\mathrm{cd}}$ is the effective compressive strength of the concrete inclined struts;

- $z$ is the internal lever arm;

- $f_{\mathrm{ywd}}$ is the design yield stress of shear reinforcement;

- $A_{\mathrm{sw}}$ is the cross-sectional area of the shear reinforcement.

$\theta$ should be chosen between the following recommended limits:

$$
1 \leq \operatorname{ctg} \theta \leq 2.5
$$

The value $\theta_{\mathrm{d}}$ of $\theta$ that makes the stirrups yield and, at the same time, the web concrete reach its compression strength can be obtained by equalling the relations (1) and (2) and, in the case of $\alpha=90^{\circ}$, it results:

$$
\operatorname{ctg} \theta_{\mathrm{d}}=\sqrt{\frac{v f_{\mathrm{cd}} b_{\mathrm{w}}}{f_{\mathrm{ywd}} \frac{A_{\mathrm{sw}}}{s}}-1}
$$

The coefficient $\nu$ is an efficiency factor which allows for the actual distribution of the stress within the inclined struts and the effect of cracking. This factor is defined by technical standards and it is calibrated on the reinforcement detailing prescribed in the codes. For example, Eurocode 2 [6] assumes:

$$
v=0.60\left[1-\frac{f_{\mathrm{ck}}}{250}\right]
$$

where $f_{\text {ck }}$ (in $\mathrm{MPa}$ ) is the characteristic compressive cylinder strength of concrete.

In order to verify the reliability of the relations recommended in the present codes with respect to the failure loads measured in tests, numerical analyses have been performed using the ultimate resistance values of the materials.

The following data have been adopted:

- ultimate values of the material strength;

- $f_{\text {c,cube }}=24.80 \mathrm{MPa}$;

- $f_{\mathrm{c}}^{\text {c,cube }}=0.83 \times f_{\text {c,cube }}=20.58 \mathrm{MPa}$ (compressive cylinder strength of concrete according to Ref. [13]);

- $f_{\mathrm{t}}=407.70 \mathrm{MPa}$;

- $c_{\text {inf }}=2.0 \mathrm{~cm}$ (bottom cover on longitudinal reinforcement);

- $z=0.90 \times d$ (where $z$ is the internal lever arm and $d$ is the effective depth of the cross section). 


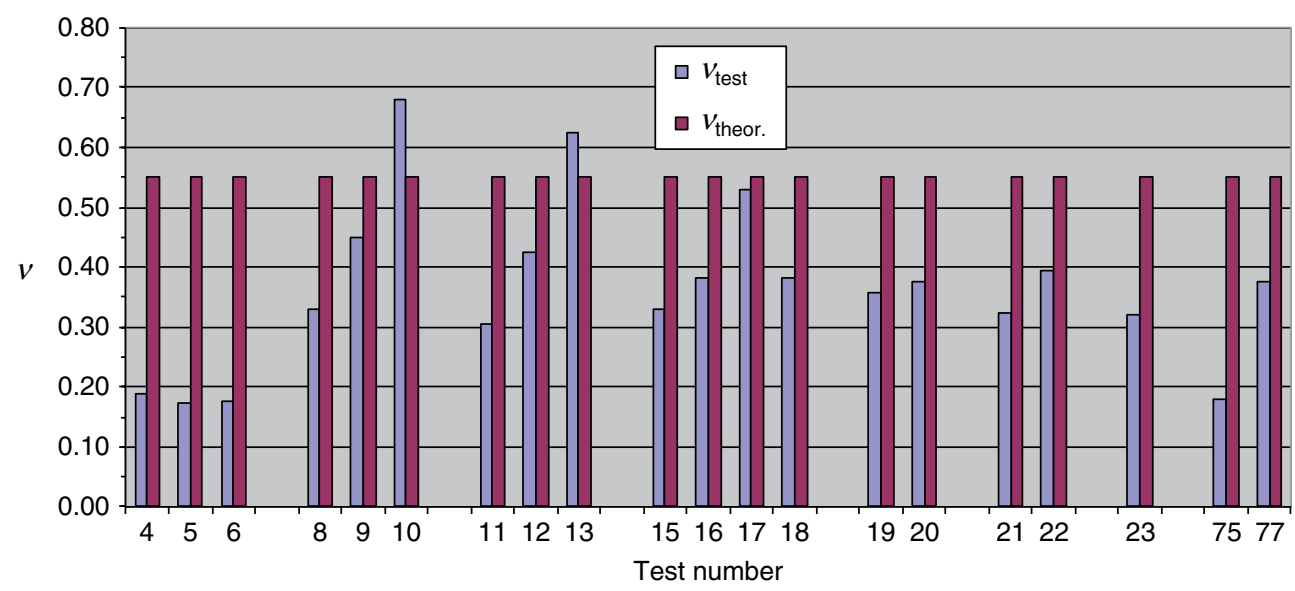

Figure 1: $\nu_{\text {test }}$ and $\nu_{\text {theor }}$.

From relations (1), (2) and (4), assuming that the theoretical shear strength is equal to the test shear strength, the value $\nu_{\text {test }}$ of $\nu$ has been evaluated and the results are shown in Fig. 1. This figure shows that, almost in all the examined cases, the calculated theoretical value $\nu_{\text {theor. }}$ of $\nu$ is bigger than the one $\left(\nu_{\text {test }}\right)$ calculated from the test ultimate load. The average value of $\nu_{\text {test }}$ is equal to 0.37 with a coefficient of variation of 0.36 , while $\nu_{\text {theor. }}$ is always equal to 0.55 . This means that $\nu_{\text {theor. }}$ is about $34 \%$ bigger than the average value of $\nu_{\text {test }}$.

In Fig. 2 the values of the ultimate shear $V_{\text {u,test }}$ measured in the tests and that $\left(V_{\mathrm{Rd}, \text { ctg } \theta}\right)$ calculated using relations (1), (2), (4) and (5) are shown. $V_{\mathrm{Rd}, c t g \theta}$ has been evaluated ignoring the limits on $\operatorname{ctg} \theta$ of Eurocode 2 . This figure highlights that the theoretical value $\left(V_{\mathrm{Rd}, \operatorname{ctg} \theta}\right)$ overestimates, almost in all the cases, the test ultimate shear strength. The average value of the ratio of $V_{\text {Rd,ctge }}$ to $V_{\text {utest }}$ is equal to 1.45 with a coefficient of variation equal to 0.29 .

Moreover, Fig. 3 shows that, almost in all the examined cases, the theoretical value $\left(\operatorname{ctg} \theta_{\text {theor }}\right)$ of $\operatorname{ctg} \theta$ is higher than the one $\left(\operatorname{ctg} \theta_{\text {test }}\right)$ calculated from the test ultimate load. Thus, it follows that the beams tested by Mörsch in the early 20th century did not have the capacity to reach the values of $\operatorname{ctg} \theta$ recommended by the present codes.

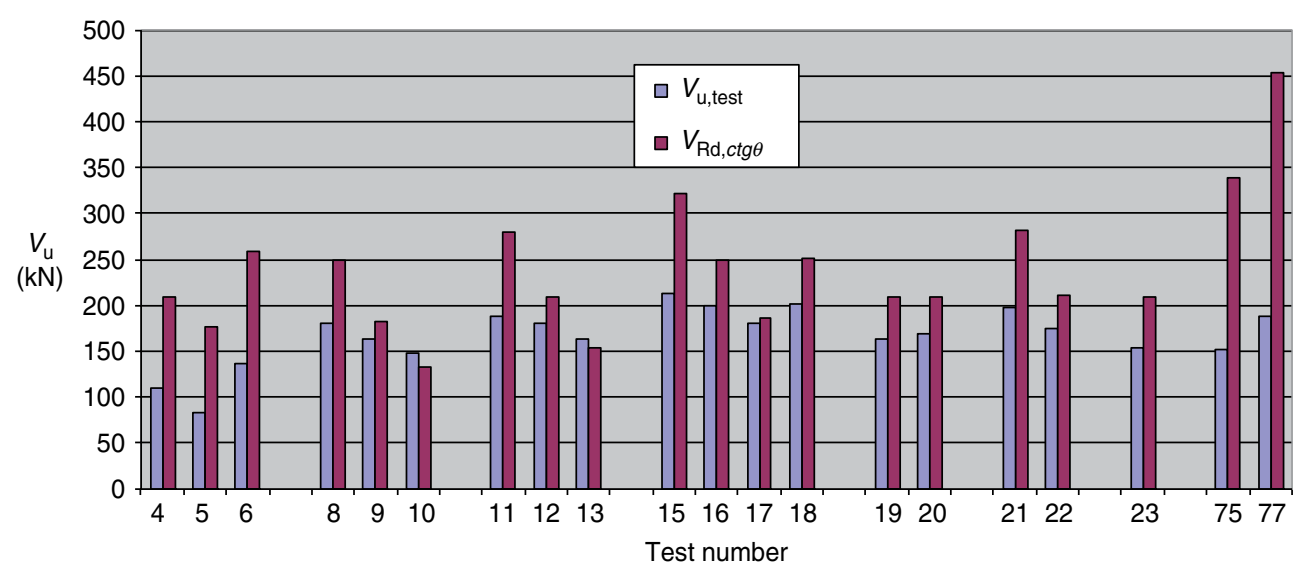

Figure 2: $V_{\mathrm{u}, \text { test }}$ and $V_{\mathrm{Rd}, c \operatorname{tg} \theta}$. 


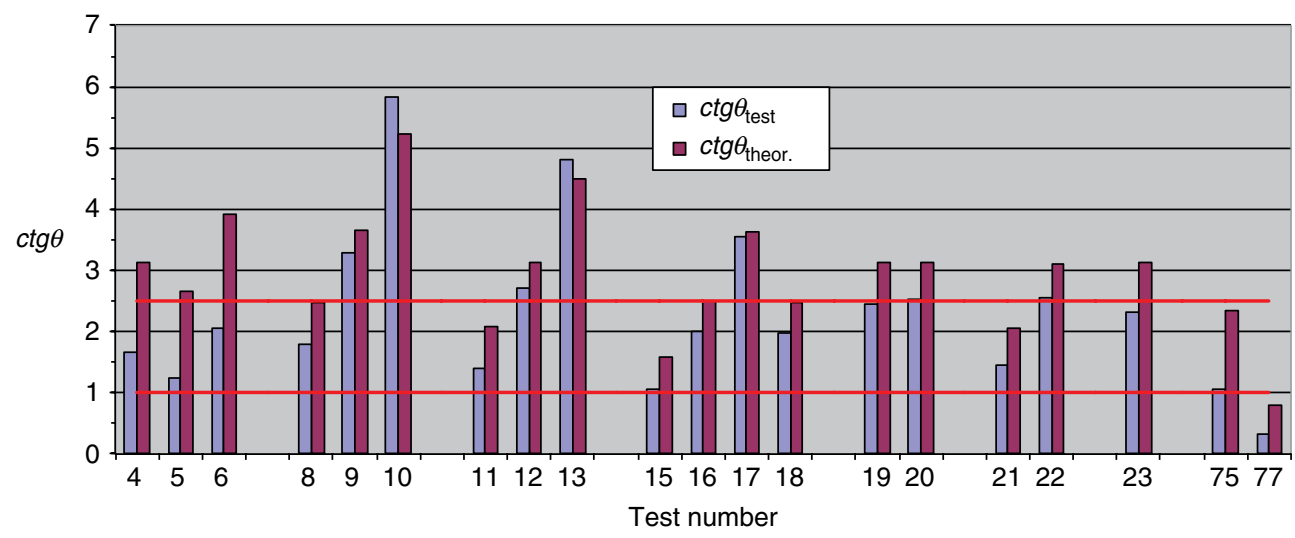

Figure 3: $\operatorname{ctg} \theta_{\text {theor }}$ and $\operatorname{ctg} \theta_{\text {test }}$ (horizontal lines indicate the limits according to Eurocode 2) [6].

It is worth noting that the 'truss model with variable strut angle', that in the Eurocode 2 [6] (but also in the Italian Technical Standards [13]), has substituted the 'modified hyperstatic truss model', is principally based on the following assumptions:

- the ultimate resistance of the inclined struts should be reached when the shear reinforcement has yielded;

- the shear reinforcement should have the capacity to limit the opening of cracks in order to make them be crossed by struts having an inclination $\theta$ lower than the one corresponding to first cracking.

The second assumption could not be satisfied by RC beams of the early 20th century. In fact, steel reinforcement used in the past had ductility characteristics higher than those of the present reinforcement. This means that, because of the large deformations consequent to yielding, crack widths are so excessive to make impossible the transfer of shear forces across them. Consequently the 'truss model with variable strut angle' with the present limit of the maximum value of $\operatorname{ctg} \theta$ is not applicable to beams of the past. This consideration is noteworthy because present codes that deal with the assessment of existing structures use the same shear strength relations adopted for the design of new structures. This means that it is necessary to differentiate the approach, trying to find the values of the maximum limit of $\operatorname{ctg} \theta$ consistent with the test results reported in the literature regarding beams having reinforcement similar to the one used in the early 20 th century.

In the draft version [7] (no more in force) of Eurocode 2, as in the previous Italian technical standards [14], the shear capacity was evaluated using the 'modified hyperstatic truss model'.

According to this approach the shear resistance is evaluated under the assumption of $\theta=45^{\circ}$, calculating the web tension strength separately from the web compressive strength. In particular the first one is the summation of the concrete strength $\left(V_{\text {cd }}\right)$ and of the shear reinforcement strength $\left(V_{\mathrm{yd}}\right)$ :

$$
V_{\mathrm{Rd}, \mathrm{s}}=V_{\mathrm{cd}}+V_{\mathrm{yd}}
$$


Many codes used to assume $V_{\text {cd }}$ equal to the value calculated for beams without shear resistance. This assumption, generally on the safe side, is difficult to be justified because it is based on the hypothesis that in the element with shear reinforcement the 'dowel effect' and the 'aggregate interlocking effect' give the same contribution that they would give if the element had no shear reinforcement. Moreover, when the beam has shear reinforcement, the flexural resistance of the 'concrete cantilever' between two following cracks is strongly reduced by the very low spacing of the shear cracks; hence the contribution of the 'concrete cantilever' resistance to the shear strength in a beam with shear reinforcement is less than that in a beam without shear reinforcement. Especially because of the difficulty to evaluate the contribution of $V_{\text {cd }}$ in the relation (6), the present codes have adopted the 'truss model with variable strut angle' in which the resistance of the 'concrete cantilever' is not considered (the contribution of $V_{\text {cd }}$ misses) and the web tension strength is only due to shear reinforcement but, at the same time, inclined struts can have $\theta \leq 45^{\circ}$. This model seems to be more consistent with the results of tests performed on present beams but, as previously showed, seems to loose reliability for beams of the early 20 th century.

To compare these two models, for the beams of Table 1, web tension shear strength $V_{\text {Rd3,ENV1992-1-1 }}$ has been calculated using the ultimate resistance values of the materials and according to the 'modified hyperstatic truss model' of the old draft of Eurocode 2 [7]:

$$
V_{\mathrm{Rd} 3, \mathrm{ENV} 1992-1-1}=V_{\mathrm{Rd} 1}+V_{\mathrm{wd}}
$$

where

- $V_{\mathrm{wd}}=f_{\mathrm{ywd}} \frac{A_{\mathrm{sw}}}{s} z$;

- $V_{\mathrm{Rd} 1}=\tau_{\mathrm{Rd}} \cdot k \cdot\left(1.2+40 \cdot \rho_{\mathrm{ld}}\right) \cdot b_{\mathrm{w}} \cdot d$;

- $\tau_{\mathrm{Rd}}=0.25 \cdot f_{\mathrm{ctm}}$;

- $f_{\mathrm{ctm}}=0.30 \cdot f_{\mathrm{ck}}^{2 / 3}$;

- $k=(1.6-d) \geq 1.0(d$ in $\mathrm{m})$;

- $\rho_{\mathrm{ld}}=\frac{A_{\mathrm{s} 1}}{b_{\mathrm{w}} \cdot d} \leq 0.02$;

- $A_{\mathrm{sl}}$ is the area of the tensile reinforcement, which extends not less than $\left(l_{\mathrm{bd}}+d\right)$ beyond the section considered (with $l_{\mathrm{bd}}$ design anchorage length of reinforcement).

From Fig. 4 it is worth noting that, almost in all the examined cases, the 'modified hyperstatic truss model' of the old draft of Eurocode 2 [7], confirming what previously discussed, gives results that are more similar to those of the laboratory tests. In particular the average value of the ratio of $V_{\text {Rd3,ENV1992-1-1 }}$ to $V_{\text {u,test }}$ is equal to 1.26 with a coefficient of variation equal to 0.47 .

\section{THE TRANSVERSAL SHEAR BEHAVIOUR}

In this paragraph the interpretation of the transversal shear behaviour is showed by using the LPM.

Born as a method to design Strut-and-Tie Models [15] in reinforced concrete (RC) structures the LPM [8] is a clear and effective technical instrument of investigation and judgement.

So far the LPM has been used for a wide range of applications: RC structures [8, 16], masonry structures [17-20], seismo-resistant structures [21], progressive collapse [22], assessment of existing constructions [23-25]. 


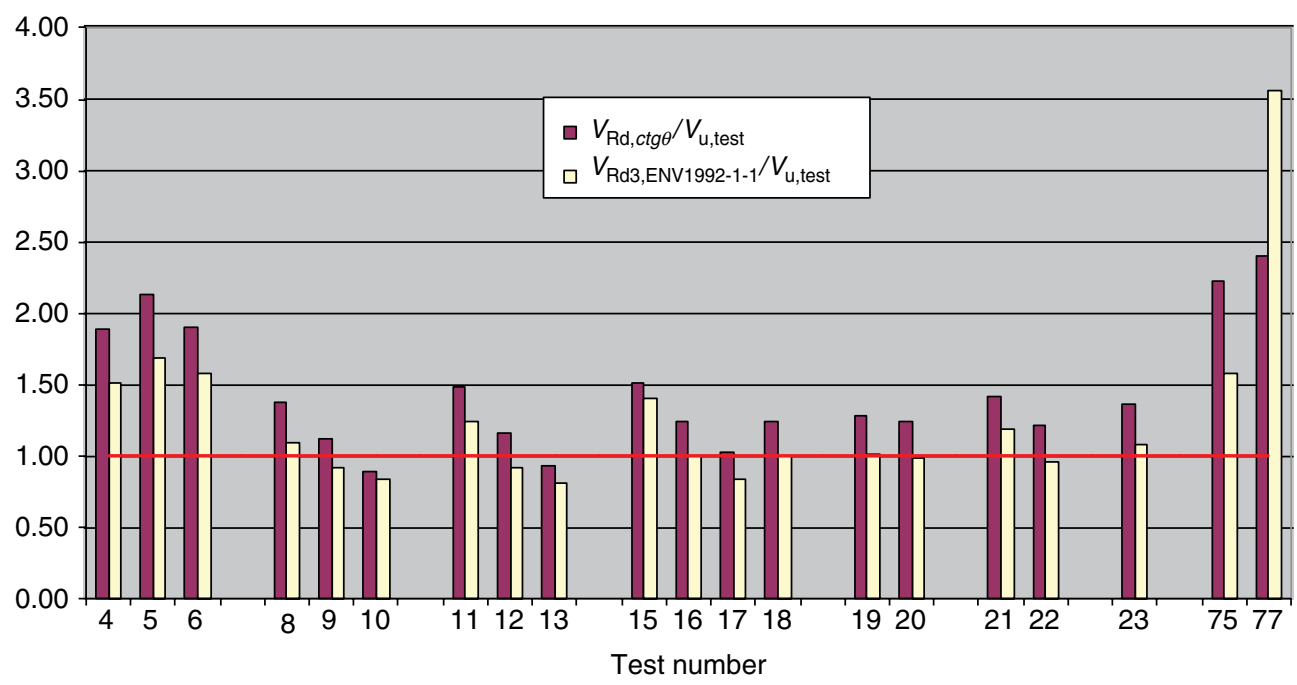

Figure 4: Ratio of the shear capacity $\left(V_{\mathrm{Rd}, \operatorname{ctg} \theta}\right)$ according to Eurocode 2 [6] and of the web tension shear strength $\left(V_{\mathrm{Rd} 3, \mathrm{ENV} 1992-1-1}\right)$ according to the old draft of Eurocode 2 [7] to the test ultimate shear strength $\left(V_{\text {u,test }}\right)$.

In the transfer of forces within a structure or an element, from their point of origin $(S)$ to their ends $(E)$, deviations in the load path direction can occur causing a thrust $(H)$; for equilibrium to be maintained, a reactive force must be applied that is equal in magnitude and opposite in direction to this thrust (Figs 5 and 6).

The load path represents the line along which a force or a force component (more precisely: the component of a force in a chosen direction, for example the vertical component of a load) is carried through a structure from the point of loading to its support. The force component ( $F$ in Fig. 5) associated with a load path remains constant on its way through the structure; as a consequence of this definition, thrust $H$ must be perpendicular to the travelling
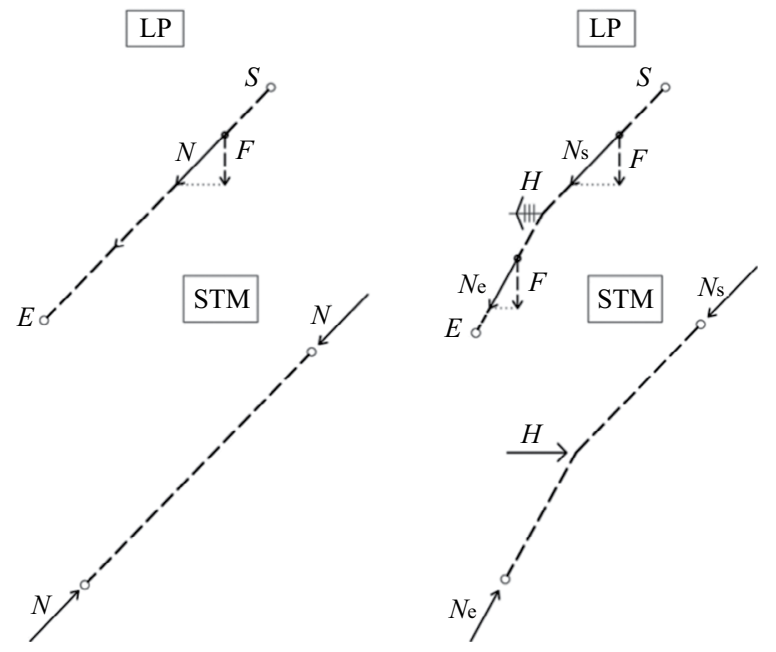

Figure 5: Load Path (LP) and Strut-and-Tie Models (STM). 


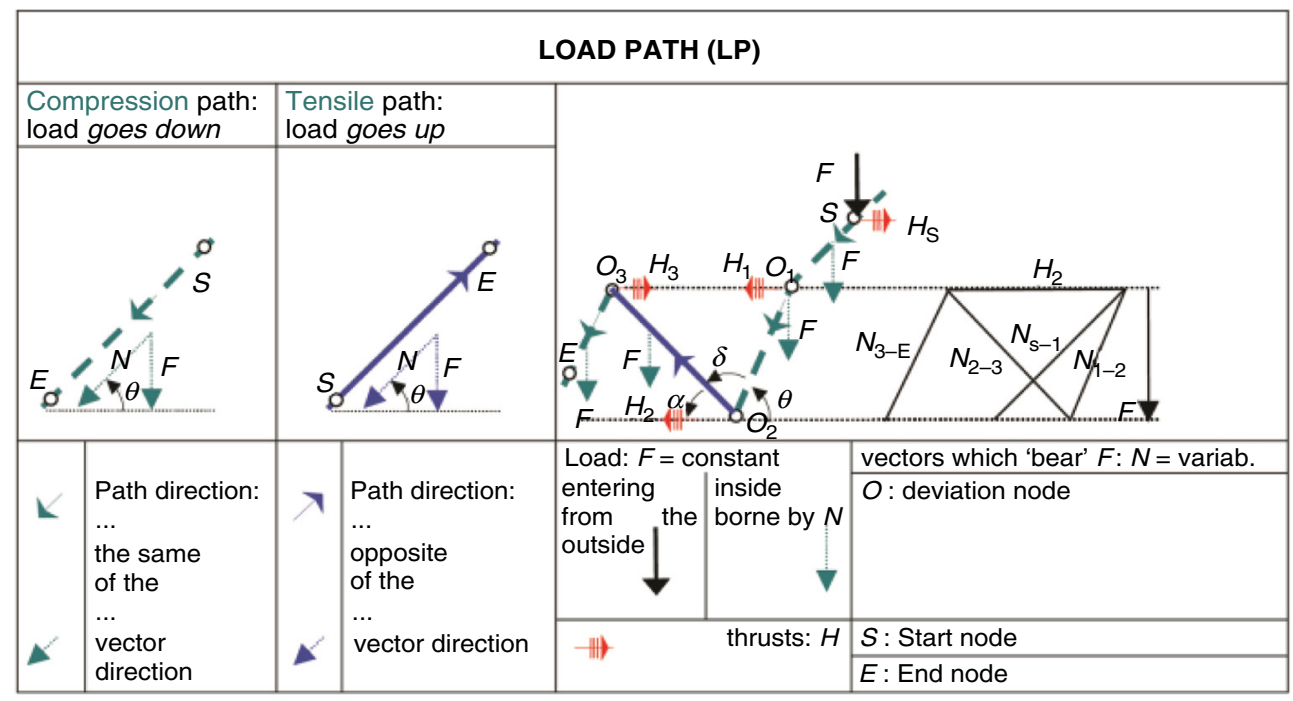

Figure 6: Load Path: symbols.

load $F$. The design of this load flowing through the structure can be approximated by polygonal lines in which there are thrusts in every deviation node.

It follows that, according to the model, the structure will be crossed by fluxes in compression (dashed lines), when loads travel in the same direction of their path, and by fluxes in tension (continuous lines) along which loads go in the opposite direction with respect to their path (Fig. 6). According to the classical theory, the basic principles of the LPM are the respect of both equilibrium and consistency. Thrusts in deviation nodes are necessary in order to respect equilibrium and every path is possible if it is in equilibrium.

Among infinite paths in equilibrium, loads have to choose the one in which their vectors invest the minimum quantity of strain energy $(D)$, that is the only one both consistent and in equilibrium.

The total invested strain energy is

$$
D=\frac{1}{2} \int_{V} \sigma \varepsilon d V
$$

where $V$ is the integration domain, $\sigma$ and $\varepsilon$ are the stress and the strain vector, respectively.

Along a generic path, that is polygonal in this model, the calculus of the invested strain energy $(D)$ is simplified in the summation of the terms relevant to each side of the truss:

$$
D=\sum_{i} D_{i}
$$

where $i$ is the generic side of the load path.

For instance, if linear elastic constitute laws for materials are assumed as well as constant transversal section of each side, the elementary strain energy $D_{i}$ is

$$
D_{i}=\frac{1}{2} N_{i} l_{i} \varepsilon_{i}
$$

where $i$ is the generic side of the load path, $N_{i}$ is the intensity of the vector that bears the travelling load on that side, $l_{i}$ is the length of the generic side and $\varepsilon_{i}$ is the mean strain on that side. 
In the assumption of linear elastic constitute laws for materials with Young's Modulus equal to $E$, if the transversal section of a side is linearly variable from $A^{(1)}{ }_{i}$ to $A^{(2)}{ }_{i}$ (e.g. half of a bottle-shaped strut) the elementary strain energy $D_{i}$ is

$$
D_{i}=\frac{1}{2} \frac{N_{i}^{2} l_{i}}{E\left(A_{i}^{(1)}-A_{i}^{(2)}\right)} \operatorname{Ln}\left(\frac{A_{i}^{(1)}}{A_{i}^{(2)}}\right)
$$

From Fig. 6 it is possible to notice that the relation between the travelling load $F$ and its vector $N$ is

$$
N=\frac{F}{\sin \theta}
$$

where $\theta$ is the inclination of the path. If $\theta$ decreases, $N$ increases; this means that the condition with $\theta$ nil is not consistent because it will produce an infinite value of $N$ and, hence, of the strain energy $D$. The consequence of this consideration is that a travelling load cannot move orthogonally to itself. The only possibility for the travelling load to move in the orthogonal direction is to follow a path composed by inclined descending and ascending sides.

For further details about the LPM, see references [16-25].

A simplified model of the diagonal compressive flux in an element subjected to shear and bending is showed in Fig. 7. The flux starts from the longitudinal compression zone (on the top of the beam in Fig. 7) and, in the descending path, it keeps itself spread in all the web

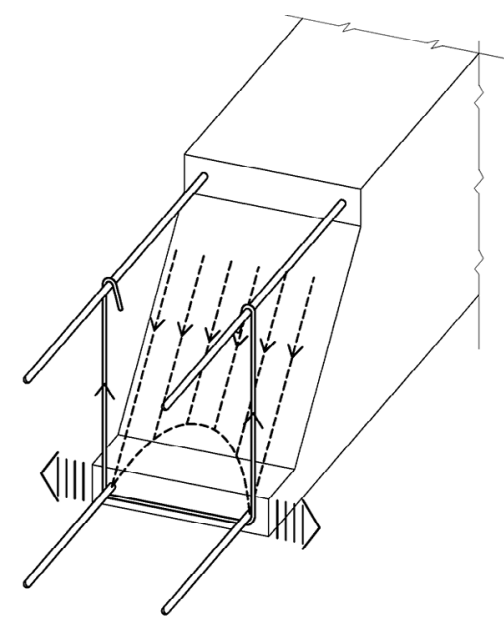

(1)

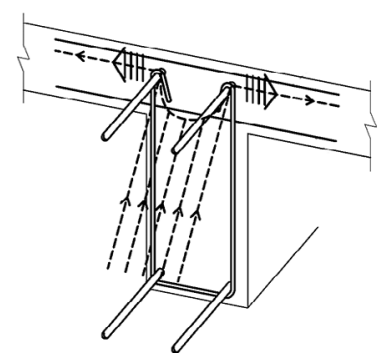

(II)

Figure 7: Shear transversal behaviour of a beam (axonometric view). 
width in order to save strain energy. However, it is obliged to concentrate on the longitudinal bars that are the only one able to carry the horizontal longitudinal thrusts due to the deviation of the shear path. This concentration can happen thanks to the formation of a transversal arch; in this model, transversal thrusts arise and they can find equilibrium because of the transversal horizontal link of the stirrup. In the absence of this link the only way, for these thrusts, to find equilibrium is to use the concrete tension strength. Detail (II) of Fig. 7 shows that the presence of a floor slab, offering a compression path to the transversal top thrusts, makes possible the adoption of top open stirrups.

Beams of the early 20th century often had U-shaped links as stirrups (Fig. 8); this means that, for the transversal bottom thrust, equilibrium can be maintained only thanks to concrete tension strength.

Figure 8 shows a model to analyse transversal behaviour for beams with U-shaped links. The most critical condition is where the bottom lateral transversal thrust $\left(H_{\text {end }}\right)$ is applied. The ultimate shear for the transversal behaviour $\left(V_{\mathrm{Rd}, \text { lat }}\right)$ is given by the capacity of concrete cover to carry the transversal thrusts using its tensile strength and avoiding the ejection of the longitudinal bars.

In this model the following assumptions have been made:

(a) $\operatorname{cgt} \theta^{\prime}$ should not be less than an assumed value $\operatorname{cgt} \theta_{\min }$;

(b) the deviation of the inclined struts in the bottom of the beam web starts from a distance $h / 2$ (Fig. 8) from the top of the beam if $\operatorname{cgt} \theta^{\prime}>\operatorname{cgt} \theta^{\prime}{ }_{\text {min }}$;

(c) the stress in the inclined strut is constant;

(d) the forces in every U-shaped link are equal;

(e) $H_{\text {end }}$ divided itself into two identical parts (Fig. 9): one crosses $a_{\text {sup }}$ and the other one crosses $a_{\text {inf }}$;

(f) $\gamma$ is the angle of the transversal (Fig. 9) and longitudinal diffusion of $H_{\text {end }}$ within the concrete (Fig. 10).

The reason for the assumption (a) is that, if the overall depth of the beam is very large with respect to its width, the inclined strut, in order to save strain energy, tends to deviate in the bottom of the beam; a limit on the minimum value of $\operatorname{ctg} \theta$ is needed to take account of this consideration. This limit could be taken equal to that $\left(\operatorname{cgt} t{ }^{\prime}{ }_{\min }=0.5\right)$ usually assumed in the design of deep beams and column footings.

As a consequence of assumptions (c) and (d), the inclined strut should be divided into a number of parts equal to the number of U-shaped links.

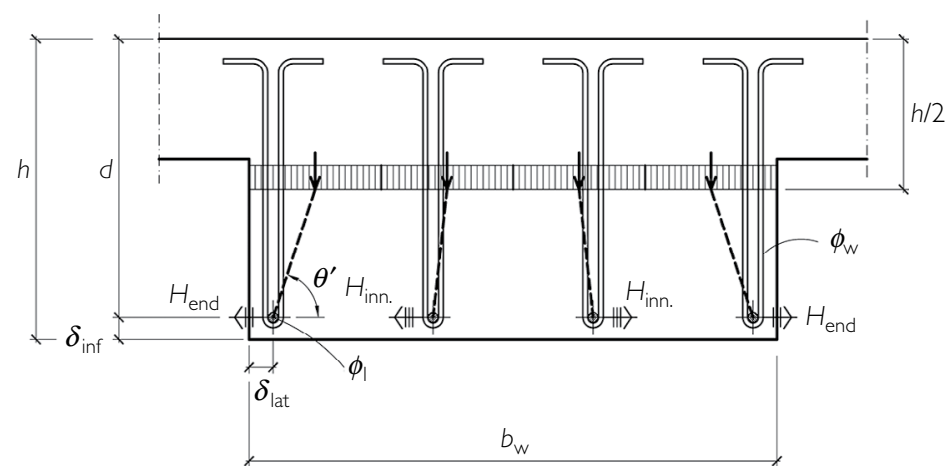

Figure 8: Analysis model of shear transversal behaviour of a beam with U-shaped links (cross-section view). 


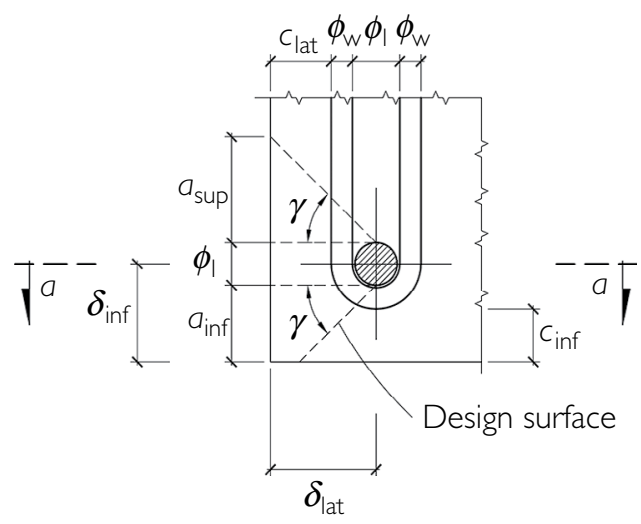

Figure 9: Left bottom node detail of the beam in Fig. 8.

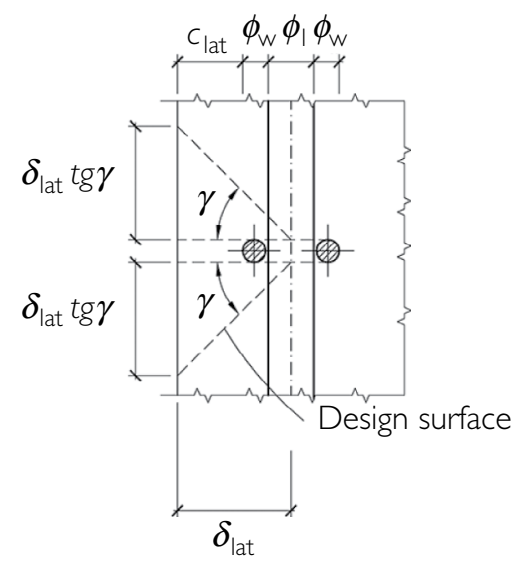

Figure 10: Cross section of the detail in Fig. 9.

The resistance of the concrete cover is governed by the minimum value $\left(a_{\text {transv,min }}\right)$ between $a_{\text {sup }}$ and $a_{\text {inf }}$ (Fig. 8). Because of the assumption (e) the strength value $H_{\text {end,max }}$ of $H_{\text {end }}$ is

$$
H_{\text {end,max }}=f_{\text {ctd }} \cdot\left(2 \cdot a_{\text {transv, min }}\right) \cdot a_{\text {long, min }}
$$

where

- $f_{\text {ctd }}$ is the design value of the axial tensile strength of concrete;

- $a_{\text {long,min }}=\min \left[2 \cdot \delta_{\text {lat }} \cdot \operatorname{tg} \gamma,\left(s-\phi_{\mathrm{w}}\right)\right]$ is the longitudinal width of the diffusion area of $H_{\text {end }}$;

- $\delta_{\text {lat }}=c_{\text {lat }}+\varphi_{\mathrm{w}}+\frac{\varphi 1}{2}$;

- $s$ is the longitudinal spacing of shear reinforcement;

- $f_{\text {фे }}$ is the shear reinforcement diameter. 
Because of the assumption (d) the total force $F_{\mathrm{s}, \max }$ carried by a stirrup composed by a total number $n_{\mathrm{w}}$ of links is

$$
F_{\mathrm{s}, \max }=H_{\text {end, } \max } \frac{n_{\mathrm{w}}}{2} \frac{1}{\operatorname{ctg} \theta^{\prime}}
$$

and the ultimate shear of the transversal behaviour is $\left(V_{\mathrm{Rd}, \mathrm{lat}}\right)$

$$
V_{\mathrm{Rd}, \mathrm{lat}}=F_{\mathrm{s}, \max } \frac{z}{s} \operatorname{ctg} \theta_{\mathrm{d}}
$$

where $\operatorname{ctg} \theta_{\mathrm{d}}$ is given by relation (4) and $z$ is the internal lever arm.

An application of this model is showed in Figs 11 and 12. The following data have been used:

- design values of the material strength;

- $f_{\text {ck,cube }}=20 \mathrm{MPa}$ (characteristic compressive cubic strength of concrete);

- $f_{\text {ck }}=0.83 \times f_{\text {ck.cube }}=16.60 \mathrm{MPa}$ (characteristic compressive cylinder strength of concrete according to [13]);

- $f_{\mathrm{cd}}=0.85 \times f_{\mathrm{ck}} / 1.5=9.41 \mathrm{MPa}$ (design compressive strength of concrete);

- $f_{\mathrm{ctd}}=0.70 \times\left(0.30 \times f_{\mathrm{ck}}^{2 / 3}\right) / 1.5=0.91 \mathrm{MPa}$ (design tensile strength of concrete);

- $f_{\mathrm{yk}}=215.00 \mathrm{MPa}$ (characteristic yield strength of reinforcement);

- $f_{\mathrm{yd}}=f_{\mathrm{yk}} / 1.15=186.96 \mathrm{MPa}$ (design yield strength of reinforcement);

- $\nu=0.60\left(1-f_{\mathrm{ck}} / 250\right)=0.56$

- $\phi_{\mathrm{w}}=6 \mathrm{~mm}$;

- $n_{\mathrm{w}}=4$

- $s=15 \mathrm{~cm}$;

- $\operatorname{ctg} \theta_{\min }^{\prime}=0.5$;

- $\gamma=45^{\circ}$;

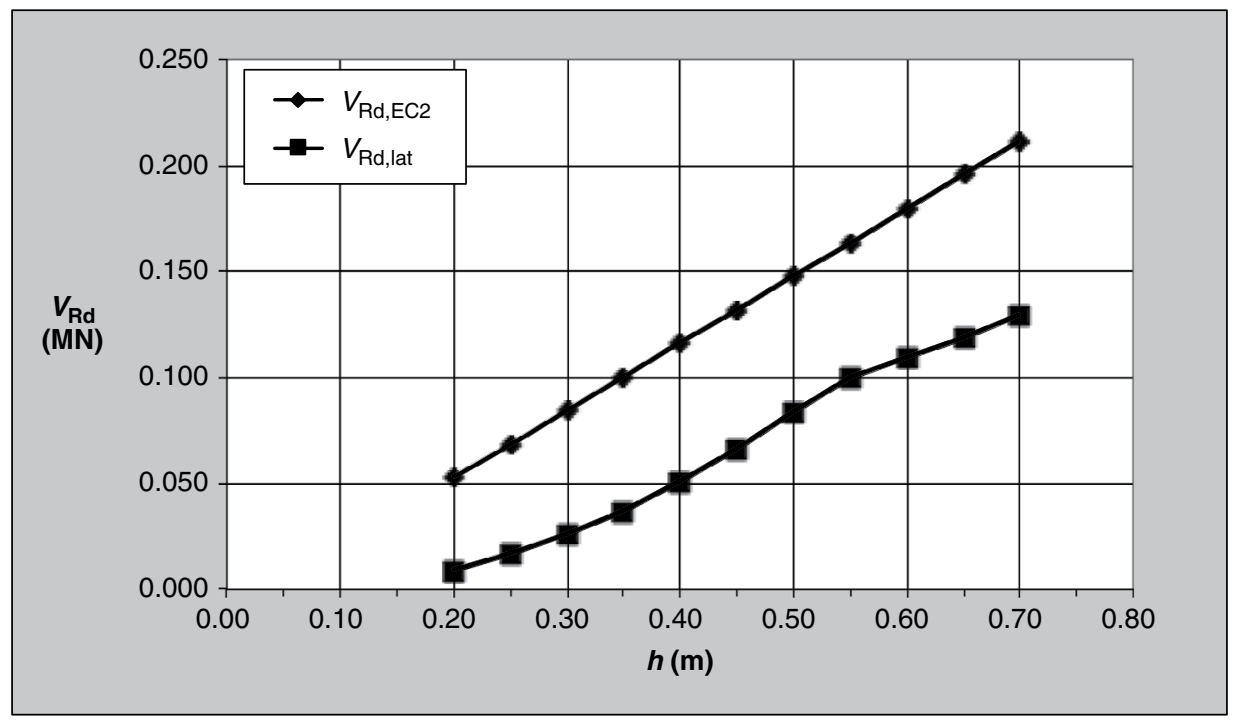

Figure 11: $V_{\mathrm{Rd}, \mathrm{EC} 2}$ and $V_{\mathrm{Rd}, \text { lat }}$ for a beam with $b_{\mathrm{w}}=30 \mathrm{~cm}$ and $h=$ var. 


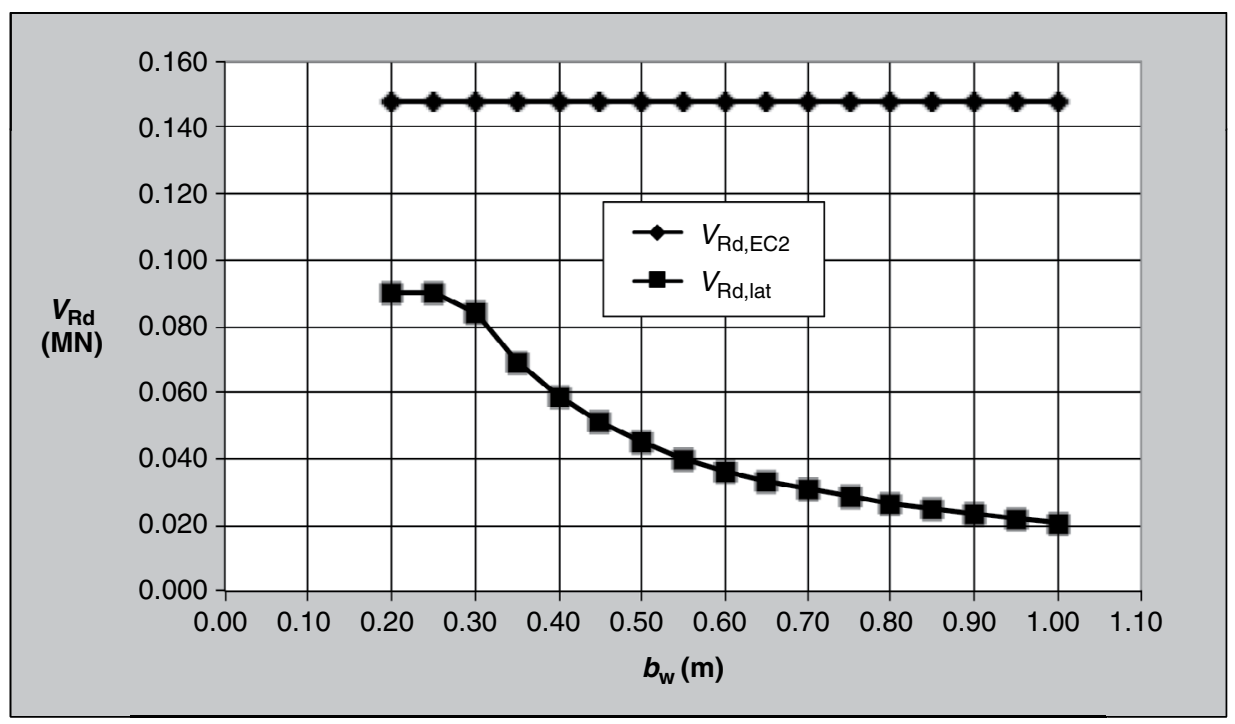

Figure 12: $V_{\mathrm{Rd}, \mathrm{EC} 2}$ and $V_{\mathrm{Rd}, \text { lat }}$ for a beam with $b_{\mathrm{w}}=$ var. and $h=50 \mathrm{~cm}$.

- $z=0.90 \times d$ (where $z$ is the internal lever arm and $d$ is the effective depth of the cross section);

- $\phi_{1}=16 \mathrm{~mm}$;

- $c_{\text {lat }}=2.0 \mathrm{~cm}$;

- $c_{\text {inf }}=2.0 \mathrm{~cm}$.

In the cases of Fig. $11 b_{\mathrm{w}}=30 \mathrm{~cm}$, whereas $h=50 \mathrm{~cm}$ in the cases of Fig. 12. In these figures the comparison between the shear capacity $\left(V_{\mathrm{Rd}, \mathrm{EC} 2}\right)$ evaluated according to Eurocode 2 [6] (which neglects the transversal behaviour) and the one $\left(V_{\mathrm{Rd}, \text { lat }}\right)$ calculated taking account only of the transversal behaviour is showed.

It is worth noting that in the case of Fig. 12, larger value of $b_{\mathrm{w}}$ means lower value of $\theta$, (since $n_{\mathrm{w}}$ is constant) and hence lower value of shear capacity for transversal behaviour.

According to the proposed approach, the shear capacity of the section is the minimum value between the two calculated resistances. In both cases the shear capacity is governed by the transversal behaviour.

\section{CONCLUSIVE REMARKS}

In this preliminary study, the results of the tests performed on RC beams by Mörsch [1] in the early 20th century seem to show that the relations of the present codes used to evaluate shear resistance for new structures cannot be used without any modification for 'historical' RC beams.

Firstly, because of the great ductility of steel reinforcement used in the past, the historical beams cannot reach the inclination values of the diagonal struts recommended by the present codes. Secondly, the type of shear reinforcement (i.e. open U-shaped links) makes the transversal behaviour collapse anticipate the one provided by standard formulations calibrated on beams with stirrups. 
Regarding the longitudinal shear behaviour, relations of the old Eurocode 2 [7] seem to be more reliable than those of the last Eurocode [6]. However both codes tend to overestimate the shear capacity of historical RC beams.

Moreover the approach proposed in this article for the transversal shear behaviour has shown that often the shear capacity of beams with U-shaped links is governed by the transversal behaviour.

It follows that particular attention has to be paid especially because, at present, the economical and social weight of the structural assessment of existing constructions is becoming particularly relevant.

However, given that this is a preliminary study based on a small subset of experiments, only verified with two codes, these conclusions cannot be considered as general and, hence, further work is needed in order to analyse other shear tests performed on historical beams taking also account of other formulations for shear capacity.

\section{REFERENCES}

[1] Mörsch, E., Der Eisenbeton, seine Theorie und Anwendung, Stuttgart, Germany, 1923.

[2] Talbot, A.N., Tests of Reinforced Concrete T-Beams. Bulletin No. 12 of the University of Illinois, Engineering Experiment Station, Urbana, IL, 1906.

[3] Talbot, A.N., Tests of reinforced concrete beams: resistance to web stresses. Bulletin No. 29 of the University of Illinois, Engineering Experiment Station, Urbana, IL, 1909.

[4] Hellebois, A. \& Espion, B., Structural weaknesses of the Hennebique early reinforced concrete system and possible retrofitting. Structural Engineering International, 23(4), pp. 501-511, 2013. DOI: 10.2749/101686613X13627347100275

[5] Foti., D., Shear vulnerability of historical reinforced-concrete structures. International Journal of Architectural Heritage, 9(4), pp. 453-467, 2015. DOI: 10.1080/ 15583058.2013.800920

[6] European Committee for Standardization (CEN), EN 1992-1-1:2004 Eurocode 2. Design of Concrete Structures. Part 1-1: General Rules and Rules for Buildings, 2004.

[7] European Committee for Standardization (CEN), ENV 1992-1-1:1992 Eurocode 2. Design of Concrete Structures. Part 1-1: General Rules and Rules for Buildings, 2004.

[8] Schlaich, J., Schafer, K. \& Jennewein, M., Toward a consistent design of structural concrete. PCI Journal, 32(3), pp. 74-150, 1987. DOI: 10.15554/pcij.05011987.74.150

[9] Fédération internationale du béton (Fib), Seismic assessment and retrofit of reinforced concrete buildings. Bulletin 24, 2003.

[10] Mezzina, M., Palmisano, F. \& Raffaele, D., A simplified procedure to evaluate seismic vulnerability of R.C. circular bridge piers. Bridge Maintenance, Safety, Management, Resilience and Sustainability (Proceedings of the 6th International Conference on Bridge Maintenance, Safety and Management - IABMAS 2012, Stresa, Italy, July 8-12 2012), eds. F. Biondini \& D.M. Frangopol, Taylor \& Francis Group: London, pp. 3525-3532, 2012.

[11] Beninato, F., Foti, D. \& Vacca, V., U.L.S. 3d domain of rectangular cross-sections in R.C. subject to shear and torsion. Engineering Structures, in print.

[12] Fédération internationale du béton (Fib), Model code 2010. Final draft. Volume 2. Bulletin, 66, 2012.

[13] Ministero delle Infrastrutture e dei Trasporti (MIT). D.M. 14.01.2008. Approvazione delle Nuove Norme Tecniche per le Costruzioni, 2008. 
[14] Ministero dei Lavori Pubblici (MLP), D.M. 09.01.1996, Norme tecniche per il calcolo, l'esecuzione ed il collaudo delle strutture in cemento armato normale e precompresso e per le strutture metalliche, 1996.

[15] Ritter, W, Die Bauweise Hennebique. Schweizerische Bauzeitung, 7(33), pp. 59-61, 1899.

[16] Palmisano, F., Alicino, G., Vitone, A., Nonlinear analysis of R.C. discontinuity regions by using the bi-directional evolutionary structural optimization method. Proceedings of the OPT-I, An International Conference on Engineering and Applied Sciences Optimization, eds. M.G. Karlaftis, N.D. Lagaros, \& M. Papadrakakis, National Technical University of Athens, Athens, Greece, pp. 749-758, 2014.

[17] Palmisano, F., Interpretation of the behaviour of masonry arches and domes by simple models. Structural Studies, Repairs and Maintenance of Heritage Architecture XIII (WIT Transactions on the Built Environment 131), ed. C.A. Brebbia, WIT Press: Southampton, pp. 233-244, 2013.

[18] Palmisano, F. \& Elia, A., Behaviour of masonry buildings subjected to landslide-induced settlements. International Journal of Structural Engineering, 5(2), pp. 93-114, 2014. DOI: 10.1504/IJSTRUCTE.2014.060891

[19] Palmisano, F. \& Elia, A., Shape optimization of strut-and-tie models in masonry buildings subjected to landslide-induced settlements. Engineering Structures, 84, pp. 223-232, 2015. DOI: 10.1016/j.engstruct.2014.11.030

[20] Palmisano, F., Rapid diagnosis of crack patterns of masonry buildings subjected to landslide-induced settlements by using the Load Path Method, International Journal of Architectural Heritage, 10(4), pp. 438-456, 2016. DOI: 10.1080/15583058.2014.996922

[21] Palmisano, F. \& Elia, A., A procedure for the detailing design of simply supported R.C. bridge decks subjected to in-plane actions. Proceedings of the COMPDYN 2015, 5th ECCOMAS Thematic Conference on Computational Methods in Structural Dynamics and Earthquake Engineering, Crete Island, Greece, 25-27 May 2015, eds. M. Papadrakakis, V. Papadopoulos, \& V. Plevris, pp. 3530-3544, 2015.

[22] Palmisano, F., Mitigation of progressive collapse by the activation of the elasto-plastic catenary behaviour of R.C. slab structures. The Open Construction \& Building Technology Journal, 8, pp. 122-131, 2014. DOI: 10.2174/1874836801408010122

[23] Palmisano, F., Methodology for rapid structural vulnerability assessment for service loads at the territorial scale. Journal of Performance of Constructed Facilities, 30(4), pp. 04015079/1-9, 2016. DOI: 10.1061/(ASCE)CF.1943-5509.0000826

[24] Palmisano, F. \& Vitone, A., A meaningful case of a collapse caused by hidden structural defects. Structural Engineering International, 25(3), pp. 308-318, 2015. DOI: 10.2749/ $101686615 X 14210663188330$

[25] Palmisano, F. \& Vitone, A., Partial collapse of one of the most important historical buildings in Salerno, Italy. Journal of Performance of Constructed Facilities, 29(6), pp. 04014164/1-13. DOI: 10.1061/(ASCE)CF.1943-5509.0000658 